\section{No Child Left Behind Act} of 2001

Matthew H. Holcomb ${ }^{1}$ and David E. McIntosh ${ }^{2}$

${ }^{1}$ Department of Pharmacology, Virginia

Commonwealth University, Richmond, VA, USA

${ }^{2}$ Department of Special Education, Teachers

College, Bell State University, Muncie, IN, USA

\section{Synonyms}

Public law no. 107-110, "nicklebee"

\section{Definition}

The No Child Left Behind Act of 2001 (NCLB) is a controversial federal education reform law aimed at improving student achievement and changing the culture of American schools. Specifically, the law reauthorized the Elementary and Secondary Education Act of 1965 (ESEA) and was designed to increase accountability for student achievement, promote scientifically driven curriculum, expand parental options, and increase local control over educational content. To accomplish this, NCLB requires states and school districts to define standards for basic proficiencies, develop standardized assessments to be given to students, and ensure that all public school teachers are qualified to teach approved curricula.

In 2015, the NCLB Act was replaced by the Every Student Succeeds Act which relocated administration of the program from the Federal government to the states.

\section{Cross-References}

- Individuals with Disabilities Education Improvement Act of 2004

\section{References and Reading}

No Child Left Behind: www2.ed.gov/nclb/landing.jhtml U.S. Department of Education: www.ed.gov 